\title{
HÖLDERLIN Y LA RELIGIÓN
} HÖLDERLIN AND RELIGION

\section{HÖLDERLIN E A RELIGIÃO}

Andrés Alfredo Castrillón Castrillón*

\section{RESUMEN}

Este artículo tiene el propósito, en un primer momento, de dilucidar la noción de religión y mito en Friedrich Hölderlin, contrastándolo con el concepto de religión racional de Kant. En un segundo momento, se comparará la concepción de este poeta con algunos estudiosos del tema religioso posteriores a él. Además, se sostiene que la reflexión sobre la religión que realiza Hölderlin es vigente, pese a su poca influencia en los análisis actuales del fenómeno.

\section{PALABRAS CLAVE}

Religión, Poesía, Mito, Filosofía, Hölderlin.

\section{ABSTRACT}

The article aims, first, to explain the ideas of religion and myth in Friedrich Hölderlin's thought by contrasting them with Kant's concept of rational religion. Second, it compares Hölderlin's idea of religion with that of some experts on religion who came

* Magíster en Literatura colombiana de la Universidad de Antioquia, 2011. Docente de la Facultad de Educación y Humanidades de la Fundación Universitaria Luis Amigó, Medellín, Colombia. Docente de cátedra del Instituto de Filosofía de la Universidad de Antioquia, Medellín, Colombia. Pertenece al grupo de investigación Filosofía y Teología Crítica de la Fundación Universitaria Luis Amigó. El artículo se deriva de la investigación "Hölderlin y la religión".

Correo electrónico: andrescastrillon1@gmail.com, andres.castrillonca@amigo.edu.co, http://orcid.org/0000-0002-5136-9997

Artículo recibido el 29 de marzo de 2016 y aprobado para su publicación el 9 de noviembre de 2016. 
after him. It is also argued that the thoughts of Hölderlin regarding religion are still useful and valid despite the minor influence he has in the current analyses of that particular phenomenon.

\section{KEY WORDS}

Religion, Poetry, Myths, Philosophy, Friedrich Hölderlin.

\section{RESUIMO}

Este artigo propõe, em um primeiro momento, dilucidar a noção de religião e mito em Friedrich Hölderlin, em contraste com o conceito de religião racional de Kant. Em um segundo momento, será comparada a concepção do poeta com alguns estudiosos do tema religioso posteriores a ele. Além disso, afirma-se que a reflexão que realiza Hölderlin sobre a religião é vigente, apesar da pouca influência que tem nas análises atuais do fenômeno.

\section{PALAVRAS-CHAVE}

Religião, Poesia, Mito, Filosofia, Hölderlin. 
Sobre el dios moral de Kant y el dios mítico poético de Hölderlin

- Qué repercusión tienen el mito y la poesía en la religión? ¿Son estos el fundamento o esencia de la religión? Más aún, ċcómo pueden ser aquellos el fundamento o esencia de esta? Hölderlin sostiene que los hombres quieren recordar y agradecer su existencia, la cual experimentan vinculada a algo superior, irrepresentable e inconcebible por el pensamiento y que, no obstante, tienden a pensar y representar. El mito contiene elementos históricos e intelectuales mediante los cuales se puede conceptualizar lo que se expresa en sus imágenes; además la interacción de estos elementos permite reiterar, en la vida cotidiana, la experiencia de una "más alta conexión" (Hölderlin, Ensayos 97), de una vivencia que se resiste a una determinación exclusivamente lógica.

Al respecto, dice Van der Leeuw que: "El mito no es otra cosa que la palabra misma" ( Fenomenología 398). Es decir, las vivencias expresadas en el mito pueden ir de un individuo a otro hasta conformar una comunidad, o permanecer vivas por la pertenencia de estos a una comunidad ya establecida. Pero cuando se perpetúan bajo una institución, debido a la fijación a unas leyes que las convierten de este modo en positivas, se produce un estancamiento y decadencia de dichas relaciones, deviniendo en un agotamiento de la base común de las religiones.

Mas cuando emergen nuevos mitos se contribuye al dinamismo de las religiones, a la adecuación de "la más alta conexión" con los periodos históricos en los que se vive; de lo contrario la religión decae y permanece ejercida por sucesión familiar o por castas o por profesión, lo que deriva en un trabajo calculado y mecánico. El mito alberga una multiplicidad que se constituye en la fuente renovadora de la relación del hombre con la naturaleza y con lo que llama divino. Relación que corresponde a una detención de la vida habitual, diaria, en un sentimiento que parece rebasar el discurrir cotidiano sin anularlo. A la satisfacción de una necesidad fisiológica o biológica, sobreviene un placer físico que cesa momentos después; a la satisfacción de una necesidad mucho más compleja como lo sería esta "conexión más alta", adviene un placer mucho mayor, y con 
ello la sensación de que la vida se detiene en esta alegría, que proyecta en el hombre una momentánea irrelevancia de todo lo fisiológico y mecánico, según Hölderlin.

Este momento de detención de la vida biológica - que superaría la experiencia intelectual -, puede ser compartido por diferentes individuos en una comunidad, incluso a partir de ella podría conformarse una diferente. Nuevos mitos, nuevos rituales, nueva congregación hasta que se repita la positividad de la religión y la nueva emergencia de mitos. La divinidad, cuya fuente es la naturaleza, permanece constantemente en su actividad; de esta constancia dan cuenta los hombres, según el cambio del periodo histórico que les corresponda vivir, pensar y representar, tal como lo expresa Hölderlin en el ensayo "El devenir en el perecer" (105).

Al contrario de Kant - y de la tradición especulativa en torno a las pruebas de la existencia de Dios, conocida como teología natural, en la que se concebía la prueba de la existencia de Dios, o que Dios es, en virtud de la razón natural por medio de silogismos y proposiciones lógicas -, Hölderlin recurre a la poesía. Si bien Kant es asertivo en la imposibilidad de derivar de las conexiones mecánicas, ordenadas según la ley causal, la existencia de Dios, con la misma contundencia, deja claro en qué ámbito sí se puede pensar la existencia de un ser necesario. Es decir, no se puede deducir la existencia de Dios ni desde la directa observación ni desde lo a priori y con ello aseverar que él es; se debe proceder desde la consideración racional de una voluntad buena y de un ser necesario. Kant direcciona el pensamiento sobre Dios hacia un ámbito moral, afín a la idea del supremo bien, y plantea el posible y remoto vínculo con Dios por medio del cumplimiento de la ley racional práctica; así se deriva un fundamento moral para la religión con validez universal.

Las creencias, así como las opiniones, solo conducen a errores si no están regidas por el conocimiento erudito, aunque aquellas expresen normas de comportamiento. Una religión racional, cuyo fin es el obrar moral de los sujetos autónomos vinculada con la clara y precisa interpretación de las Escrituras, es la pretensión ilustrada de Kant - tal como lo expresa en su libro de 1793, La religión en los límites de la mera razón (136142) -. "Los filósofos morales [dice Kant] entre los griegos y luego entre 
los romanos hicieron poco a poco eso con su doctrina fabulosa de los dioses", él se refiere a una instrucción en principios universales a partir de una fe moral. Y continúa:

[...] El más grosero politeísmo supieron explicarlo al fin como una mera representación simbólica de las propiedades del ser divino uno, y atribuir a las diversas acciones viciosas, o incluso a las fantasías bárbaras pero bellas de sus poetas, un sentido místico que acercaba una creencia popular $[\ldots]$ a una doctrina moral comprensible para todos los hombres y única provechosa (138).

"La religión racional" que "es 'el espíritu de Dios, que nos guía en toda verdad" (113) se opone a esta desviación popular y politeísta de la divinidad. En ella, y en los eruditos que cuidan de las Escrituras y las hacen compresibles al pueblo, radica el vínculo de la religión con la moralidad en su sentido más puro. Queda descartado todo elemento mitológico 'pagano' que no esté al servicio de una fe pura, racional.

Así lo reafirma Kant cuando dice:

La fe religiosa pura es ciertamente la única que puede fundar una iglesia universal; pues es una fe racional, que se deja comunicar a cualquiera para convencerlo, en tanto que una fe histórica basada solo en hechos no puede extender su influjo más que hasta donde pueden llegar, según circunstancias de tiempo y lugar, los relatos relacionados con la capacidad de juzgar su fidedignidad. Pero una particular debilidad de la naturaleza humana tiene la culpa de que no se pueda contar nunca con esa pura fe tanto como ella merece, a saber: fundar una iglesia sobre ella sola (2012-128).

Tres años después de la publicación del libro de Kant y al contrario de este, Hölderlin en su ensayo "Sobre la religión" de 1796, critica el deseo de ilustración y racionalidad que tiene recelo de las creencias populares y de las manifestaciones poéticas y politeístas. Luego de la afirmación "Sería, así, poética según su esencia toda religión"” (Hölderlin 103), en tanto sus representaciones "[...] no son ni intelectuales ni históricas,

1 Aseveración que supone una base poética en la religión unida al mito, propio de pueblos antiguos o de pueblos que renuevan sus creencias y la comprensión de su entorno en virtud de la conservación y transformación de este tipo de relatos. 
sino intelectuales históricas, esto es: míticas, tanto por lo que toca a su material como por lo que toca a su exposición" (Hölderlin 103). Más adelante dice el poeta sobre el vínculo entre religiones: "Aquí se puede aún hablar acerca de la unión de varias religiones en una, allí donde cada uno venera en representaciones poéticas su dios y todos uno comunitario, donde cada uno festeja míticamente su propia vida más alta y todos una vida más alta comunitaria, la fiesta de la vida" (103).

Es evidente que hay una distancia entre estos autores; mientras Kant demanda la fe pura como fundamento de la religión, Hölderlin apela al sentimiento mítico poético; en tanto que Kant rechaza el acontecimiento histórico para fundamentar la creencia, Hölderlin recurre al hecho de que es este suceso, transformado por el mito, el sustento de la religión; mientras Kant aspira a una religión ilustrada concebida para aplicar una moralidad racional al servicio del sumo bien, Hölderlin piensa en una "ilustración más alta" (100) que comprende el sentimiento y el pensamiento, lo racional e irracional, inadmisible solo a través del entendimiento; y en tanto Kant apela a la universalidad de la religión -cristiana indirectamente-, Hölderlin lo hace a las relaciones religiosas. Así, la religión se transforma y se crea a partir de los hombres y las situaciones históricas.

La universalidad de la religión racional de Kant genera una exclusión que no esta en la universalidad de las relaciones religiosas de Hölderlin, pues si "cada uno tiene su propia esfera" (100) con lo más alto y además la puede compartir con otros, hasta conformar incluso una religión universal, esta última no radicaría en la universalidad de la razón ni en la pretensión de fijar lo que es y debe ser, sino en conllevar la esfera más alta del otro; esta universalidad consistiría en asemejarse a la experiencia que alguien puede tener de tal esfera.

Allí radica lo propio de las relaciones religiosas: en la interacción de los hombres entre sí y con aquello que experimentan como lo 'más alto'. En consecuencia, las leyes no escritas -que se derivan de la acción recíproca entre el hombre y su esfera- no se fundamentan en la universalidad de las leyes de la razón ni en máximas morales, o en la tendencia al principio bueno, evitando el malo; lo hacen en los requerimientos históricos que cada comunidad tenga en su contexto socio-cultural. 
En Kant se podría ubicar el dios judeo-cristiano en su versión pietista; en Hölderlin, que también era pietista, por el contrario no se halla exclusivamente este dios. La reflexión de su ensayo no se identifica con un dios específico ya que habla del "dios del mito" ("Sobre la religión" 103), que cambia según el contexto y la época. No se trata del Dios representado en la tradición occidental, ejemplo de ello es que tanto en su novela Hiperión o el eremita en Grecia, como en sus elegías El archipiélago, Lamentos de Menón por Diotima, Pan y vino, por mencionar algunas, las alusiones a dios o a los dioses no se limitan a reproducir el mito antiguo, estos tienen elementos novedosos.

Así, considera que la solución de los conflictos de un periodo determinado, si requiere elementos sacros para dinamizar y ampliar la actividad del hombre, necesita la renovación de las relaciones religiosas, que tienen su fundamento en nuevos mitos. Estos últimos pueden ser racionales sin que deriven en leyes positivas o en una ley moral racional, que se considera como más alta que las prácticas morales de los antiguos, por ejemplo, las representadas en los mitos.

Por otro lado, en lo que atañe al dios de Kant, este es un dios en esencia moral; por su parte, el dios de Hölderlin es mítico-poético y por ello mismo deviene y se transforma, motivo por el cual estas relaciones religiosas son progresivas y no reactivas. Las no pocas alusiones a la Grecia antigua, los nuevos mitos que recrea este poeta con nombres griegos y la admiración por ese remoto pasado clásico, no lo constituyen en un reaccionario ni en un defensor de la religión cristiana, como se comprueba en la siguiente afirmación: "cada uno tendría su propio dios, en la medida en que cada uno tiene su propia esfera, en la cual actúa y que él experimenta” (Hölderlin, "Sobre la religión" 100); aquí bien pudiera pensarse en un dios personal que no es exclusivamente el dios cristiano ${ }^{2}$-. Dicha esfera puede ser compartida por los hombres en tanto actúen y padezcan "humanamente, esto es: elevados por encima de la necesidad" (100-101), y en esa medida tendrían "una deidad comunitaria" (101).

2 Por lo menos no en este ensayo "Sobre la religión", otra cosa pueden indicar los poemas Patmos o El único, por ejemplo. 
Finalmente, mientras que para Kant "[...] sólo la fe religiosa pura, que se funda enteramente en la razón, puede ser reconocida como necesaria, por lo tanto como la única que distingue a la iglesia verdadera" (143), para Hölderlin, en virtud de la esencia poética, puede darse "[...] la unión de varias religiones en una, allí donde cada uno venera en representaciones poéticas su dios y todos uno comunitario" ("Sobre la religión"103). En opuesta tendencia a la fe religiosa pura, este poeta da prioridad a las representaciones míticas, a una creencia que involucra por igual lo intelectual y lo histórico sin necesidad de separar los ámbitos nouménico y sensible, porque ambos estarían unidos y representados en el mito.

Pero los nombres que Hölderlin asigna a sus personajes, los títulos de varios de sus poemas, ¿no indican una añoranza por el pasado en lugar de una transformación? Sí, pero esta añoranza de la época pasada la vincula con la época moderna a través de una dialéctica histórica que busca resolver la oposición entre lo antiguo y lo moderno ${ }^{3}$. Resolución que debería aportar al modo como el hombre transforma su pensamiento y su representación del mundo, así como sus diversas relaciones o prácticas sociales, en virtud de un arte que renueve la religión y al hombre 4 .

\section{La pervivencia de lo mítico racional: Hölderliny algunos contemporáneos}

En los libros en los que Mircea Eliade estudia el fenómeno religioso y mítico, y en los que analiza las celebraciones religiosas vinculadas a los mitos, su supervivencia y la implicación e importancia en el plano social

3 Para ampliar esta referencia véase el capítulo VI. "La experiencia excéntrica y trágica de la totalidad en Hölderlin" del libro La totalidad. En Platón, Kant, Hegel, Hölderlin y Heidegger, en donde el autor Carlos Másmela analiza en detalle los elementos antiguos y modernos que Hölderlin tiene en consideración y la propuesta que lanza para la resolución de esta dialéctica histórica por medio de una poesía filosófica

4 La objeción a este pensamiento que se extiende al romanticismo lo formula Hegel cuando afirma que ni el arte ni la religión son formas convenientes para la resolución de los problemas de los hombres modernos e ilustrados. Las anteriores no logran resolver las problemáticas de su contexto, aunque puedan reflejarla y motivar reflexiones (cf. Hegel 63). 
para diferentes comunidades, no tiene en cuenta el pensamiento de Hölderlin sobre la religión y su vinculación con lo poético. Si bien, en libros como Lo sagrado y lo profano Eliade expresa la innegable presencia de lo artístico y poético en los rituales, no tiene en cuenta al poeta alemán ni sus reflexiones sobre la religión, lo mítico poético y la belleza.

En esta misma línea están otros investigadores del fenómeno religioso, de la historia de la religión y de la evolución del pensamiento y el sentimiento religioso como Rudolf Otto y Kalr-Heinz Ohlig, ambos de corte alemán. No es extraño que estos no aludan a Hölderlin en sus obras, puesto que no afecta para nada sus propósitos. Lo que sí resulta extraño es que lo planteado por este poeta se advierta, de un modo u otro, en los posteriores estudios que realizan los tres autores mencionados. En ellos se encuentran, de un modo más específico y mejor desarrollado, algunas de las ideas que Hölderlin enuncia sobre la religión en su ensayo.

Otto, Eliade y Ohlig tienen una visión de la religión mucho más amplia que la de Hölderlin, si se considera que sus estudios comprenden los ámbitos histórico, sociológico, antropológico, entre otros, para lo cual se sirven de la arqueología, la paleología y demás disciplinas, tal como lo demuestran Eliade y Ohlig en sus estudios, además de la comparación con otras culturas y tradiciones religiosas no occidentales. Como ejemplo, los libros de Eliade Mito y realidad, El mito del eterno retorno y el ya mencionado Lo sagrado y lo profano. Así mismo en el caso de Ohlig y su libro La evolución de la conciencia religiosa. La religión en la historia de la humanidad, en el que hace un recorrido desde la llamada proto y prehistoria del hombre, pasando por las altas culturas y la instauración de las religiones universales, para finalizar con la actualidad y la pervivencia de la religión y las creencias religiosas.

El aspecto mítico-poético del fenómeno religioso y de la religión esta en los análisis de los tres autores referidos, pero ninguno de ellos le da la peculiar importancia que sí le atribuye Hölderlin y que considera como el motor del cambio y pervivencia de la religión. Esto no quiere decir que nieguen el lugar emérito que tendría el mito, sino que la referencia a este es más racional y clara que la expresada por Hölderlin, a pesar de que 
Otto haya abordado el fenómeno de lo irracional de la religión con el término numinoso ${ }^{5}$.

En su libro Lo santo. Lo racional y lo irracional en la idea de Dios publicado en 1927, Otto sustenta la afirmación de que en las concepciones teístas, y especialmente en la cristiana, la idea de Dios se concibe con predicados racionales "tales como espíritu, razón, voluntad, voluntad inteligente, buena voluntad, omnipotencia, unidad de sustancia, sabiduría" (9) y que, al mismo tiempo, esta alberga aspectos irracionales referidos por este autor como lo santo o lo sacro, aunque no lo describe con precisión. Para puntualizar la diferencia entre lo racional, que procura explicar algo irracional, y lo irracional, que escapa a tal explicación emplea la palabra numinoso.

En los conceptos mencionados por Otto se advierte la tradición filosóficoteológica que motivó las incursiones en el estudio de Dios - o de la religión - en diversos autores como Leibniz, Wolff, Kant, Schleiermacher y Hegel, así como sus críticos, por ejemplo, Stirner y Feuerbach. La tesis que defiende Otto es que la religión tiene elementos que no se comprenden racionalmente aunque pueda darse un acercamiento intuitivo a estos, y que tiene otras características cuya explicación racional permiten concebir una religión más perfecta y elevada, como lo dice abierta y reiteradamente (10) - de modo que si no logra dar cuenta del elemento irracional en la religión más perfecta, la cristiana, por lo menos sí expresa afirmaciones muy discutibles como la supuesta perfección y superioridad -. Con estos elementos "es posible la fe como convicción en conceptos claros, opuesta al mero sentimiento" (Otto 10), pero, precisamente, los elementos irracionales se manifiestan a través del sentimiento. En algunos puntos concuerda Otto con Hölderlin - aunque se acerca más a la concepción de Hegel - como en las características racionales e irracionales que sobrepasan el plano de la repetición ritual. Pero Hölderlin tiene una concepción más profunda del fenómeno religioso y mitológico, aunque la expresión que hace de esta es hermética la mayor parte del tiempo.

5 Neologismo del autor para referirse a lo sagrado o santo en un sentido que rebasa el uso coloquial o institucional. Este vocablo lo deriva de las palabras latinas numen-is (deidad, divinidad, e incluso voluntad) y omnis-e (todo) (Otto 16). 
El punto de encuentro entre Hölderlin y Otto se observa en varios momentos en los que este contrasta el predominio de la explicación racional de lo santo, lo sagrado, (Das Heilige) con lo irracional y lo no captable por la razón, pero sí por el sentimiento o la emoción que desborda la claridad lógico-proposicional. Según Otto, hay un aspecto inefable de lo santo que esta en toda manifestación religiosa (14) y que resulta imperceptible para la razón. Hölderlin vincula este aspecto a "Aquellas relaciones más infinitas, más que referentes a necesidad, de la vida" que pueden "ser pensadas, pero no meramente pensadas", pues "el pensamiento no las agota" (Hölderlin 99). Y para evitar caer en un sinsentido o ser objeto de crítica al hablar de leyes no escritas, como a las que apelaba Antígona, dice que: "tiene que haberlas, si aquella conexión más alta no es un delirio" (99).

En el tema religioso o místico, y en la manifestación de la divinidad, se experimenta un desbordar o sobrepasar a la razón y a la claridad conceptual. Mas Hölderlin, a diferencia de Otto que intenta aclarar con nuevos conceptos lo irracional de la manifestación de la divinidad y lo santo (119), apela a la interacción del hombre con lo divino representado en el mito y en la conmemoración, puesto que es en esta relación donde tiene mayor sentido la dupla racional irracional, o sentimiento y razón, y no de modo exclusivo en la revelación lógica de lo santo (Hölderlin, "Sobre la religión" 103).

Eliade en Lo sagrado y lo profano considera que lo sagrado se manifiesta a través de diferentes aspectos - hierofanía - y con ello aparece incluso en lo que es considerado profano (18). Pero al hacerlo, por ejemplo en una piedra, un en árbol o en un objeto cualquiera, esta cosa pierde su concepción profana y se convierte en sacra. Según Eliade, la hierofanía suprema es la expresión de lo sagrado en un hombre: Jesucristo para los cristianos. Lo sagrado, dado su nivel de complejidad para explicarlo y comprenderlo, es vinculado por este autor con las relaciones religiosas. Las mismas de las que habla Hölderlin cuando intenta responder por qué los hombres necesitan una representación de aquello que no se deja representar ni pensar con claridad, pero que, paradójicamente, exige pensamiento y representación (97). Pese a esta semejanza, y a que en 
Hölderlin el mito sirve como fundamento de la religión, este es dinámico, y por ello depende del periodo histórico y del contexto en el que una comunidad este, en lugar de pensarse como una estructura que perviva en todas las religiones y que sirva como referencia, según la cual se puede hallar una explicación para el fenómeno religioso.

Por su parte, Ohlig, en lo tocante a la religión y a las manifestaciones de lo religioso, es más expositivo e indica que el origen del término religión deriva del latín religio-religionis que hacía referencia a "la suma de las obligaciones tabú del culto romano", así como a las "prescripciones rituales" y al acatamiento y "cumplimiento de los deberes jurídicos rituales, frente a la voluntad de los dioses" para evitar cualquier daño (15). Según él, solo en el siglo XVIII la noción de religión "[...] pasó a convertirse en una denominación global, primero del cristianismo y luego también de cualquier otra comunidad de fe y de culto surgido en el curso de la historia" (15), de modo que el término se acuña en occidente y se aplica para el resto del orbe. Así, el origen etimológico de vínculo - religare: vincular -, que se le atribuye a la palabra latina, implica el respeto a los dioses y el cumplimiento de la voluntad de los dioses. Y también lo siguiente: 1) "la constitución religiosa del hombre" (Ohlig 15); 2) las relaciones religiosas que se desprendan de dicha constitución; 3) los cultos que tienen como fin último la relación de dependencia, origen o tributo a algún dios; y 4) las relaciones o vínculo entre hombres con base en una conexión más compleja que las meramente sociales.

El punto de partida de la vinculación entre hombres en torno a la divinidad, lo sagrado o el dios es incierto, pero, en lo que se puede decir que tienen de fundamental, existe una motivación que se origina en los mitos, en los que se expresa todo lo histórico, lo intelectual, lo irracional, así como las normas que mantienen la vigencia y sujeción a la 'religión', que se pueden explicar por medio de la antropología, la sociología, la psicología según el caso, esto es, por medio de una interpretación racional. En todo su libro, Ohlig expone el posible inicio de las concepciones de dios, aunque en ocasiones vincula de manera forzada las esculturas halladas de culturas primitivas con una representación de lo divino, que no de dios, sin profundizar en el estudio sobre el mito. A este le atribuye un 
factor relevante, más no decisivo, de la consolidación de la naturaleza comunitaria de la religión (Ohlig 16).

No hace falta señalar que la reflexión de Hölderlin no está en el marco de los actuales análisis e interpretaciones que se basan en estudios arqueológicos, sociológicos y antropológicos al destacar la evolución de las nociones de dios, divinidad, dioses, religión; su pensamiento sobre la religión es una respuesta a un destinatario del que no se revela el nombre y en la que Hölderlin intenta decir por qué los hombres tienden a unas acciones de agradecimiento hacia algo superior denominado como la "más alta conexión" (97). Tampoco tiene Hölderlin la capacidad de indicar a fondo, con precisión y con el conocimiento histórico que se ha adquirido desde el siglo pasado - ni era su pretensión hacerlo - del avance en el conocimiento de dios desde una filosofía de la religión. No obstante, la respuesta que este poeta proporciona tiene tanta vigencia como los actuales estudios sobre la filosofía o fenomenología de la religión, con las obvias deficiencias de su texto. Su objeto se centraba en dar respuesta a por qué el hombre se representa una supuesta conexión más alta con su mundo y una imagen de su destino, que según Pau es la pregunta de por qué el hombre piensa "que Dios existe" (190).

Al respecto, en el ensayo "Sobre la religión" dice Hölderlin lo siguiente:

Ni solo partir de sí mismo, ni únicamente a partir de los objetos que lo rodean, puede el hombre experimentar que hay en el mundo más que un discurrir mecánico, que hay un espíritu, un dios, pero sí puede experimentarlo en una relación más viviente, elevada por encima de las necesidades, relación en la que él se sostiene con aquello que le rodea (100).

La pregunta que antecede a esta afirmación no reposa en 'ċexiste dios?', como dice Pau, sino en ¿Por qué los hombres tienen la necesidad de representarse algo que no se presenta ante los sentidos y para la que no tendrían los medios de concebirlo racionalmente? Más ¿Cómo sería tal representación? ¿Mediante los mitos y la poesía? o cंes una representación de orden lógica? Por otro lado, el hombre experimenta que hay "un espíritu, un dios" (100) o una relación viviente más elevada entre él y su entorno 
y su comunidad, pero no solo desde sí mismo ni desde las cosas que lo rodean, es decir, no desde un aspecto solo numinoso como lo concibe Otto, en el que se sacraliza una piedra, un árbol, un animal o a un hombre, ni tampoco desde la definición teórica de una causalidad natural ni de una práctica, sino desde la suposición de algo que rebasa la explicación conceptual racional, que constantemente Hölderlin ha llamado una más alta conexión. "En la medida [afirma] en que hay en su vida afectiva una conexión más alta, más infinita, entre él y su elemento, no puede esta conexión ser repetida ni meramente en pensamiento ni meramente en la memoria, pues el mero pensamiento por noble que sea, sólo puede repetir la conexión necesaria" (98). No obstante, el pensamiento puede ocuparse de esta conexión, aunque de un modo parcial, sin llegar a agotarla ni dominarla.

Esta conexión, por una parte, junto con la posibilidad de experimentar el mundo y el entorno como algo más que un discurrir mecánico sujeto a la ley de la causalidad natural, y por otra, independiente de la ley moral de Kant, se basa en la consideración del periodo histórico y del espacio en el que acontece el hecho a partir del que surge el mito y la reunión comunitaria 'original'. Este suceso tendría, por lo general, un individuo como referente del acontecimiento, al cual se vinculan luego los demás hombres por medio de las prácticas, la creencia en el mito y en la vitalidad que este adquiera.

Si bien puede darse una religión comunitaria apoyada en la representación del dios que compartan varios hombres, esta depende de una esfera que la mantiene viva y no de unas leyes que indiquen una positividad religiosa. Pues, dirá Hölderlin que: "[...] si hay una esfera en la que viven todos a la vez y con la cual se sienten en una relación distinta de la relación de necesidad, entonces [...] tienen todos ellos una deidad comunitaria" (101). Si existe y se experimenta, se efectuaría una práctica religiosa que contrasta con los rituales controlados por sacerdotes, pastores, etc., o, en algún caso, teólogos, al decir suyo, cuando estos hablan de una deidad y no lo hacen "de corazón" sino "a partir de una memoria servicial o por profesión” (100). 
La religión tendría, desde la perspectiva que da Hölderlin, una dinámica que supera la sujeción a una institucionalidad, y que no está sujeta solo a una comprensión racional, al modo de Kant o como se procede en la actualidad, o bien al modo de los autores antes referidos. Menos aún, en las religiones positivas como la judía, la cristiana y la musulmana en general - pese a la diversidad al interior de las mismas - y que hace parte de su pervivencia. Esta dinámica propia de una iglesia constituida a lo largo de siglos no es la que se infiere en el caso de Hölderlin, cuya característica principal sería lo mítico poético de las relaciones religiosas.

\section{La religión en el Hiperión}

La novela, Hiperión o el eremita en Grecia, es un mito solar (Kerhkof 37) que tiene como finalidad presentar la transformación que sufre Hiperión, así como el pretendido influjo que tendría este personaje en los hombres de su periodo histórico. El motivo mítico-religioso en esta obra esta en la labor educativa del héroe, que se reputa como el adalid de la renovación de los hombres moderno-ilustrados. Es un filósofo y poeta, que no cede a una sola de sus características principales, ni muy racional ni muy sentimental, pues en él hacen frente los dos armónica y disonantemente. No obstante, Hiperión es un héroe fracasado. Todas sus empresas: la político-independentista, la amorosa y la poética no se concretan como lo espera el personaje en su juventud. Y solo cuando reflexiona como hombre maduro, se transforma y comprende sus modos de actuar como un proceso dinámico que no tiene una vía unilateral ni inmediata.

Hiperión, un hombre que regresa como eremita a su patria, relata en una serie de cartas dirigidas a Bellarmino, las acciones realizadas en su juventud. Sus proyectos políticos, la amistad, el amor y demás temas estético-filosóficos, son expuestos por el narrador como expresión de su reflexión sobre su vida y el discurrir transitorio del mundo. En medio del relato, una vez ha conocido a la mujer que representará el fracaso amoroso, deciden emprender un viaje hacia Atenas -los espacios de la novela son Grecia y Alemania, aunque esta última en menor medida-. Así, 
en medio de la conmoción por estar en tan egregio lugar, se entabla un diálogo sobre lo grandioso de este pueblo en su genial medio día. "Alguien dijo: «fue debido al clima»; otro: «al arte y la filosofía»; un tercero: «a la religión y a sus formas estatales». "El arte y la religión atenienses, y su filosofía y sus formas estatales» dije yo «fueron flores y frutos del árbol, no suelo y raíces. Tomáis los efectos por la causa»" (Hölderlin, Hiperión 111).

Con este diálogo se presenta el tema de la religión en la antigüedad griega en la novela. El recuerdo del tiempo pasado le permitirá al protagonista hilvanar sus pensamientos sobre la gloria de esa Grecia espléndida y tan añorada, pero venida a menos. De lo que fue, el tiempo lo aniquiló, y lo que dejó, fue una remembranza idílica que fomenta la posibilidad de buscar la instauración de una nueva comunidad, tal como, supuestamente, aconteció entonces. Según lo dicho por el personajenarrador, la religión es el segundo fruto de la belleza, un árbol del que brotaron todas las maravillas que se sitúan en esa antigüedad dorada. No es el primer fruto porque este es el arte, la religión es solo amor al arte y a la representación de los dioses por su medio. Significativo que la religión esté en segundo lugar, pues con ello desplaza la relevancia que se le atribuye por antonomasia en las culturas en las que se ha instaurado institucionalmente, tal es el caso de la religión positiva que se denuncia, por ejemplo, en la tragedia La muerte de Empédocles: "iFuera! No puedo ver ante mí al hombre / que hace de lo sagrado industria. / Su rostro es falso y frío y muerto, / como lo son vuestros dioses" (Hölderlin 81). Estas palabras están en boca de Empédocles cuando, en la primera versión de la tragedia, se enfrenta con el sacerdote Hermócrates, quien representa toda la institucionalización y el carácter positivo de las religiones.

En el Hiperión, al contrario de la religión de los antiguos atenienses, la de los alemanes es opresora y los ha convertido en bestiales e inhumanos. Con ella, además de su cultura y estilo de vida han sido "Bárbaros [...] a quienes el trabajo y la ciencia, e incluso la religión, han vuelto más bárbaros todavía, profundamente incapaces de cualquier sentimiento divino, corrompidos hasta la médula" (204). En contraposición a esta función adversa de la religión ella es, para Hölderlin, "amor de la belleza" (113). Y aunque su momento histórico esta demarcado por la ilustración y la ciencia moderna, que parece tener prioridad sobre el sentimiento 
religioso y su expresión en nuevas formas y mitos, este poeta propone unos nuevos, además le atribuye la relevancia de educadora a la poesía antaño perdida, con este deseo escribe su novela.

"Filosofía, bellas artes, y religión, [dice Hölderlin] estas sacerdotisas de la naturaleza, actúan por lo tanto en primer lugar sobre los hombres" y más adelante señala "Otro logro de estas tres, en particular de la religión, es que el hombre [...] no se jacta de ser el Maestro y señor de la misma [la naturaleza]" (Hölderlin, Correspondencia 433). En lugar de dominarla, el hombre tiende con sus actividades a recibir "el espíritu de la naturaleza que tiene dentro" (433) con lo que puede transformar la materia y darle fuerzas. Este espíritu de la naturaleza coincide con aquella conexión más alta que experimenta el hombre en las relaciones religiosas, y se convierte en el sustento de la actividad re-creadora de su entorno por medio de las artes, la cultura, la ciencia y la filosofía.

Por último, tiene gran impacto la crítica a la saturación de la religión estatal que metafóricamente se denuncia en la novela y en la tragedia, en tanto que los modos religiosos positivos - permanentes e inmodificables pueden generar un negocio, como lo dice en una frase incompleta de su ensayo: "[...] ellos, los fundadores de religiones (si no son los padres de una familia que continúa por herencia el negocio y la habilidad de ellos)" (Hölderlin, Ensayos 104). Igual de significativo resulta la insistencia de Hölderlin en la relación de lo mítico-poético con lo religioso en su obra poética, ensayística y en su correspondencia. Hecho que se corrobora en su persistencia en la transformación del hombre a partir de la belleza y del arte. El lugar privilegiado del arte sobre la religión se evidencia en la afirmación: "según su esencia, toda religión sería poética" (103). Privilegio que tiene raíces filosóficas. Así, poesía y mitos conforman lo fundamental de toda religión.

\section{Conclusión}

El mundo visto solo como un fenómeno que se puede explicar y predecir por su discurrir mecánico, tal como se concebía hacia finales del siglo XVIII, es un lugar desacralizado o carente de elementos o características 
numinosas, puesto que lo sagrado y lo divino eran categorías que cada vez estaban más opuestas a la explicación teórica y científica. De igual modo, cada vez los mitos quedaban relegados al terreno de la imaginación, de la superstición y de periodos históricos antiguos que los ilustrados pretendían superados. No obstante, un aspecto de la religión cobró un nuevo sentido con base en las ideas ilustradas, como las de Kant, que influyeron en la concepción de las relaciones religiosas al considerarlas desde el ámbito moral. El intento del movimiento Romántico nada puede contra esta tendencia más racional que sentimental, pese a su influjo en Europa y otros lugares como América, en donde tiene una variante política muy relevante. Kant es el referente tanto en lo teórico como en lo práctico para Hölderlin; sin embargo, él, como otros coetáneos suyos, reacciona contra este tipo de concepción del mundo. Su ensayo "Sobre la religión", así como su novela y su tragedia, dan cuenta de ello.

Así, lo mítico-poético es la presentación al mismo tiempo de la forma y el contenido más básicos de las religiones. No se trata de una estructura común a todas y en todos los contextos cuando Hölderlin menciona que lo poético sería la esencia de las religiones; no lo afirma como el componente indispensable para pensarlas a manera de una estructura universal unívoca, como sucede en algunos estudiosos del fenómeno religioso del siglo XX. El mito es lo esencial como lo elemental que da vida a una creencia, y la poesía aporta a esta base al presentarla en imágenes o en tonos trágicos, épicos o líricos. En este componente mítico-poético de la religión hay muchos elementos racionales concebidos como necesarios, que son representados estéticamente, a modo de una mitología racional.

Por el contrario, una religión racional fijada en una razón pura práctica y en la comprensión de dos principios, uno bueno y otro malo, como lo pensó Kant, somete el elemento estético a la abstracción y vincula la religión a una regularidad que no está en el sentimiento natural de los hombres. La universalidad de esta religión esta anclada directamente al dominio de la razón. La que concibe Hölderlin incluye la razón, pero no como una característica exclusiva; tampoco somete lo racional al dominio ciego de lo sentimental o emocional, sino que unifica estos contrarios en lo mítico-poético al permitir re-vivir y re-interpretar el símbolo que acoge 
el mito como el elemento común a los miembros de la comunidad, sin que se agote tal relación ni en el pensamiento ni en el sentimiento.

Finalmente, la religión es un fenómeno innegable. Su centro es dios y las celebraciones en torno suyo por parte de los hombres. Pero cंqué impulsa al hombre a ello? ¿Dios? De ser así cंpor qué unos mantienen una jerarquía en esta relación? Abordar estas cuestiones y querer resolverlas es como dar movimientos circulares continuos. No obstante, la representación de dios se da o por el sentimiento o por el pensamiento que se basa en la creencia que debe haber, o no haberlo, de algo superior, o por la representación simbólica a través de mitos, o por el pensamiento racional que pretende fundamentar la necesidad de la creencia en un ser necesario. Hölderlin opta por el mito, que es el aspecto al que se acerca este texto.

\section{Lista de referencias}

Eliade, Mircea. Lo sagrado y lo profano. Barcelona: Labor, S.A., 1981.

Eliade, Mircea. El mito del eterno retorno. España: Alianza, 2000.

Kant, Immanuel. La religión en los límites de la mera razón. Madrid: Alianza, 2012.

Hölderlin, Friedrich. Correspondencia completa. Madrid: Hiperión, 1990. . Ensayos. Madrid: Hiperión, 2001. . Hiperión o el eremita en Grecia. Madrid: Hiperión, 2002. . Empédocles. Madrid: Hiperión, 2008.

Hegel, G.W.F. Filosofía del arte o estética. Madrid: Abada, 2006.

Leew, Gerardus van der. Fenomenología de la religión. México: FCE, 1964.

Másmela, Carlos. La totalidad. En Platón, Kant, Hegel, Hölderlin y Heidegger. México: Los libros de Homero, 2009.

Ohlig, Karl-Heinz. La evolución de la conciencia religiosa. La religión en la historia de la humanidad. España: Herder, 2004.

Otto, Rudlof. Lo santo. Lo racional y lo irracional en la idea de Dios. Madrid: Alianza, 1980.

Pau, Antonio. Hölderlin el rayo envuelto en canción. Madrid: Trotta, 2008. 